\title{
Testicular expression of TDRD1, TDRD5, TDRD9 and TDRD12 in azoospermia
}

\author{
Emad Babakhanzadeh ${ }^{1,2 \dagger}$, Ali Khodadadian ${ }^{1 \dagger}$, Saadi Rostami ${ }^{3}$, Iraj Alipourfard ${ }^{4,5}$, Mohsen Aghaei ${ }^{1}$, Majid Nazari ${ }^{1}$, \\ Mehdi Hosseinnia ${ }^{6}$, Mohammad Yahya Vahidi Mehrjardi ${ }^{1,2}$, Yalda Jamshidi ${ }^{7}$ and Nasrin Ghasemi ${ }^{1,8^{*}}$ (D)
}

\begin{abstract}
Background: Tudor domain-containing proteins (TDRDs) play a critical role in piRNA biogenesis and germ cell development. piRNAs, small regulatory RNAs, act by silencing of transposons during germline development and it has recently been shown in animal model studies that defects in TDRD genes can lead to sterility in males.

Methods: Here we evaluate gene and protein expression levels of four key TDRDs (TDRD1, TDRD5, TDRD9 and TDRD12) in testicular biopsy samples obtained from men with obstructive azoospermia (OA, $n=29)$, as controls, and various types of non-obstructive azoospermia containing hypospermatogenesis (HP, 28), maturation arrest (MA, $n=30$ ), and Sertoli cell-only syndrome (SCOS, $n=32$ ) as cases. One-way ANOVA test followed by Dunnett's multiple comparison post-test was used to determine inter-group differences in TDRD gene expression among cases and controls.
\end{abstract}

Results: The results showed very low expression of TDRD genes in SCOS specimens. Also, the expression of TDRD1 and TDRD9 genes were lower in MA samples compared to OA samples. The expression of TDRD5 significantly reduced in SCOS, MA and HP specimens than the OA specimens. Indeed, TDRD12 exhibited a very low expression in HP specimens in comparison to OA specimens. All these results were confirmed by Western blot technique.

Conclusion: TDRDs could be very important in male infertility, which should be express in certain stages of spermatogenesis.

Keywords: Spermatogenesis, Non-obstructive Azoospermia, piRNAs, TDRD genes

\section{Background}

Infertility remains a significant global burden [1]. Estimates suggest that $10-15 \%$ of couples worldwide experience infertility [2], with male infertility being the underlying cause in $20-50 \%$ of cases [3]. For the majority of cases however the etiology remains unknown, and is termed idiopathic infertility [4]. Azoospermia, absence of spermatozoa in the semen, is one of the most common reasons for infertility in men, with a prevalence of $1 \%$ in the general population, and over $15 \%$ in infertile men $[5,6]$. Forty percent of cases are due to male genital

\footnotetext{
* Correspondence: nghasemi479@gmail.com

†Emad Babakhanzadeh and Ali Khodadadian contributed equally to this work.

${ }^{1}$ Department of Medical Genetics, Shahid Sadoughi University of Medical Sciences, Yazd, Iran

${ }^{8}$ Abortion Research Centre, Yazd Reproductive Sicences Institue, Shahid sadoughi University of Medical Sciences, Yazd, Iran

Full list of author information is available at the end of the article
}

system blockage (obstructive azoospermia) and in the remaining cases due to low sperm production (non-obstructive azoospermia - NOA) [7, 8].

PIWI-interacting RNA (piRNA) proteins have recently been shown to play an essential role in male fertility and spermatogenesis in humans [9]. The piRNA pathwayassociated genes are highly expressed in germline cells [10]. piRNAs act by suppressing transposons and preventing their mobilization through both post-transcriptional and transcriptional mechanisms, such as degradation, chromatin remodeling, and DNA methylation [11-14].

P-element-induced wimpy testis (PIWI) proteins specifically recognize piRNAs to mediate transposon silencing. The Tudor domain of Tudor domain-containing proteins (TDRDs) have been shown to directly bind to PIWI to help regulate this process via their dimethylated arginine (sDMA) or lysine residues [15], potentially acting as a mediator or cofactor for protein-protein interactions in the

(c) The Author(s). 2020 Open Access This article is distributed under the terms of the Creative Commons Attribution 4.0 International License (http://creativecommons.org/licenses/by/4.0/), which permits unrestricted use, distribution, and reproduction in any medium, provided you give appropriate credit to the original author(s) and the source, provide a link to the Creative Commons license, and indicate if changes were made. The Creative Commons Public Domain Dedication waiver (http://creativecommons.org/publicdomain/zero/1.0/) applies to the data made available in this article, unless otherwise stated. 
piRNA pathway [16]. Twelve TDRDs have been identified in human and animal model studies, and defects in each of these can interfere with spermatogenesis [16-18].

Given the current knowledge that piRNAs and PIWI genes are involved in spermatogenesis, and the potential role of TDRDs in this process, we sought to evaluate TDRD gene expression in testicular tissue of patients with azoospermia.

\section{Methods}

\section{Study participants}

One hundred and nineteen NOA and OA men admitted to the Abortion Research Centre, Yazd Reproductive Sciences Institute, were entered into this study. All subjects were undergoing bilateral testicular tissue microdissection (mTESE) operations to attain spermatozoa for intracytoplasmic sperm injection (ICSI). The study was approved by the local Ethics Committee and written informed consent was obtained from all subjects. Preoperative tests included karyotyping and Y chromosome microdeletion analysis, and the levels of serum follicle stimulating hormone $(\mathrm{FSH})$, luteinizing hormone $(\mathrm{LH})$ and testosterone. Patients were not receiving hormone therapy and all had primary infertility. No history of TESE and cryptorchidism were reported for any of the participants. Patients with cystic fibrosis, chromosomal abnormalities and $\mathrm{Y}$ chromosome microdeletion were omitted from the study. Subjects with normal spermatogenesis were included as the control group. The best control samples were men with proven fertility, and the problem was that they never referred to infertility centers for mTESE surgery, so we used samples with normal spermatogenesis as the control group.

\section{Tissue acquisition and histological evaluation}

Following TESE, testicular samples were split into three; one was fixed in Bouin's solution for histological examination and two other sections instantly frozen in liquid nitrogen for RNA extraction and Western blot assay. Histological examination was carried out with hematoxylin and eosin (H\&E) and interpreted by a trained pathologist to classify the samples with normal spermatogenesis (OA, $n=29)$, lack of germ cells (SCOS, $n=32)$, declined number of spermatozoa (HP, $n=28)$, and incomplete maturation of germ cells (MA, $n=30$ ). No significant differences in age, LH, FSH, and testosterone serum concentrations were found between the OA, HP, MA, and SCOS groups (Table 1).

\section{RNA extraction and CDNA synthesis}

Frozen testis tissue was homogenized, and total RNA extracted using the RNeasy Plus Universal Mini Kit (Qiagen, Hilden, Germany) based on the manufacturer's protocol and then stored at $-80^{\circ} \mathrm{C}$. In-solution DNase digestion was accomplished to eliminate DNA contamination. The concentration and purification of RNA was specified using Nanodrop2000 spectrophotometer (Thermo Scientific, Wilmington, USA) and confirmed by agarose gel electrophoresis. Template cDNA was synthesized from $1 \mu \mathrm{g}$ of whole extracted RNA with Revert Aid First Strand cDNA Synthesis Kit (Thermo Scientific, Vilnius, Lithuania) using oligo dT and random hexamer primers simultaneously for each reaction in an Eppendorf Mastercycler Gradient (Hamburg, Germany).

\section{Quantitative RT-PCR}

Initial denaturation for RT-PCR started at $95^{\circ} \mathrm{C}$ for 8 min, followed by 40 cycles of denaturation at $95^{\circ} \mathrm{C}$ for $10 \mathrm{~s}$, annealing at $60^{\circ} \mathrm{C}$ for $30 \mathrm{~s}$, extension at $72^{\circ} \mathrm{C}$ for $30 \mathrm{~s}$ (Table 1). The melting curve was formed by increasing the temperature from 72 to $95^{\circ} \mathrm{C}$ to omit genomic DNA or amplification of primer dimers. qPCR was in triplicates on 48-well plates Step-One-Plus RT-PCR System (Applied Biosystems) by $1.0 \mu$ lof produced cDNA, $10 \mu \mathrm{l}$ of the SYBR Green master mix (Applied Biosystems $\mathrm{ABI} / \mathrm{PE}$, Foster City, CA), and $7.0 \mu \mathrm{l}$ of DNase/ RNase-free water, $1 \mu \mathrm{l}$ of designing primers (Table 2) for the gene expression profile. The average CT was used for further analysis, and all RT-PCR runs contained non template (cDNA) controls in order to reject potential contamination. Relative gene expression analysis was performed according to the comparative CT method: $2^{-\triangle \triangle C T}$ for TDRD1, TDRD5, TDRD9 and TDRD12. The $2^{-\triangle \Delta C T}$ parameter displays the expression fold of TDRD with respect to the housekeeping $A C T B$ gene.

Table 1 The clinical features of patient groups

\begin{tabular}{|c|c|c|c|c|c|c|}
\hline Patient groups & Number of patients & Genetic analysis & Age of patients (years) & $\mathrm{LH}(\mathrm{mlU} / \mathrm{ml})$ & $\mathrm{FSH}(\mathrm{mlU} / \mathrm{ml})$ & $\begin{array}{l}\text { Testosterone } \\
(\mathrm{ng} / \mathrm{ml})\end{array}$ \\
\hline $\mathrm{OA}$ & 29 & $46 \mathrm{XY} /$ normal AZF & $34.3 \pm 2.3$ & $8.34 \pm 1.12$ & $9.21 \pm 1.27$ & $4.41 \pm 0.34$ \\
\hline $\mathrm{HP}$ & 28 & 46XY/ normal AZF & $31.5 \pm 2.4$ & $7.92 \pm 1.18$ & $9.32 \pm 1.13$ & $4.35 \pm 0.22$ \\
\hline MA & 30 & 46XY/ normal AZF & $33.4 \pm 2.1$ & $7.93 \pm 1.35$ & $9.42 \pm 1.61$ & $4.43 \pm 0.33$ \\
\hline $\mathrm{scos}$ & 32 & 46XY/ normal AZF & $30.4 \pm 2.1$ & $8.62 \pm 1.61$ & $9.73 \pm 1.42$ & $4.45 \pm 0.34$ \\
\hline P-value & - & - & NS & NS & NS & NS \\
\hline
\end{tabular}

Values are mean \pm standard deviation

NS Non-significant, OA Obstructive azoospermia, HP Hypospermatogenesis, MA Meiotic arrest, SCOS Sertoli cell only syndrome 
Table 2 qPCR primers used in this study

\begin{tabular}{llcl}
\hline Gene & Primers $\left(5^{\prime} \rightarrow 3^{\prime}\right)$ & Product size $(\mathrm{bp})$ & TM $\left({ }^{\circ} \mathrm{C}\right)$ \\
\hline TDRD1 & F: TCCTCTTCGGTCCACAACTT & 197 & 59 \\
& R: CCTCCACATCCTTGTTTCAA & & 60 \\
TDRD5 & F: AAGTTCCCAGAGGGTTGTT & 194 & 58 \\
& R: AGAGGCTCTTATCCGCAT & & 59 \\
TDRD9 & F: GCCAGGTCTGGGTGAAATAA & 171 & 58 \\
& R:TCTGCAATATTGGTGGACAGA & & 58 \\
TDRD12 & F: TCGTTATGCAGCTTCCCTA & 172 & 57 \\
& R: CCACCTGGGTAGTTGCTTT & & 58 \\
ACTB & F: AGCACAGAGCCTCGCCTT & 172 & 60 \\
& R: AGGGCATACCCCTCGTAGAT & & 60
\end{tabular}

$b P$ Base pairs, $F$ Forward, $R$ Reverse, $T M$ Melting temperature

\section{Western blot}

Western blot examination was accomplished as formerly explained [19]. Briefly, equal amounts of proteins (35 mg) obtained from testis samples were separated with $12 \%$ SDS-PAGE and electrotransferred onto nitrocellulose paper. The membranes were blocked with $(2-5 \%)$ non-fat dry milk in $1 \mathrm{x}$ TBST $(10 \mathrm{mM} / \mathrm{L}$ Tris- $\mathrm{HCl}, \mathrm{pH} 8.0 ; 150$ $\mathrm{mM} / \mathrm{L} \mathrm{NaCl}, 0.1 \%$ Tween 20 ) for $1 \mathrm{~h}$ at $25-30{ }^{\circ} \mathrm{C}$, and then incubated with primary TDRD1(1:300; No. ABIN2373082; Antibodies-online, Aachen, Germany), TDRD5 (1:300; No. ABIN4358317; Antibodies-online, Aachen, Germany), TDRD9 (1:300; No. ABIN2373082; Antibodies-online, Aachen, Germany), TDRD12 (1:300; No. ABIN6769800; Antibodies-online, Aachen, Germany), ACTB (1:300; No. ABIN4284408; Antibodies-online, Aachen, Germany) antibody at $4{ }^{\circ} \mathrm{C}$ overnight, then with secondary goat anti-human-IgG-(H-L) antibody conjugated with horseradish peroxidase (HRP) (1:500; No. SA0000117; ProteinTech, Manchester, M3 3WF United Kingdom) for $1 \mathrm{~h}$ at $25^{\circ} \mathrm{C}$. At the end, the immunoreactive signals were determined via the ECL kit (Thermo Scientific).

\section{Statistical analysis}

The results are verified as the mean \pm SEM. Statistical analysis was done using one way anova test followed by Dunnett's multiple comparison post-test. $P$-values less than 0.05 were deemed to be statistically significant. Statistical analysis was implemented via GraphPad Prism 6 software.

\section{Results}

Histological analysis of adult testis sections with hematoxylin and eosin (H\&E) staining showed clear differences between samples (Figs. 1 and 2). Testicular TDRD gene expression was analyzed using $\mathrm{QPCR}$ and significant differences in expression observed between cases and controls. The expression of TDRD1, TDRD5, TDRD9 and $T D R D 12$ genes were significantly lower in SCOS than controls $(P<0.001$, Dunn's post-test $)$. The expression of
TDRD1 and TDRD9 was significantly lower in MA samples than controls $(P<0.001$, Dunn's post-test) (Figs. 3 and 4$)$. The expression of TDRD5 was significantly lower in all cases compared to controls ( $\mathrm{P}<0.001$, Dunn's post-test) (Fig. 5). The results showed that the expression of TDRD12 was also significantly lower in HP samples compared with controls $(P<0.001$, Dunn's post-test) (Fig. 6). The western blotting test showed the following results: TDRD1, TDRD5, TDRD9, and TDRD12 proteins were not expressed in SCOS samples. TDRD1 and TDRD9 proteins showed low expression in MA samples. The expression level of TDRD5 protein in MA and HP specimens was very low. TDRD12 protein was not expressed in HP samples (Fig. 7).

\section{Discussion}

Spermatogenesis is a complex process, involving many cell type- and stage-specific transcription factors [20, 21]. Transposons have a major impact on the architecture and function of genomes, and thus their suppression is particularly important in early stage germ cells where epigenetic control is relaxed to permit genome-wide reprogramming. The large class of TDRDs play a pivotal role in the

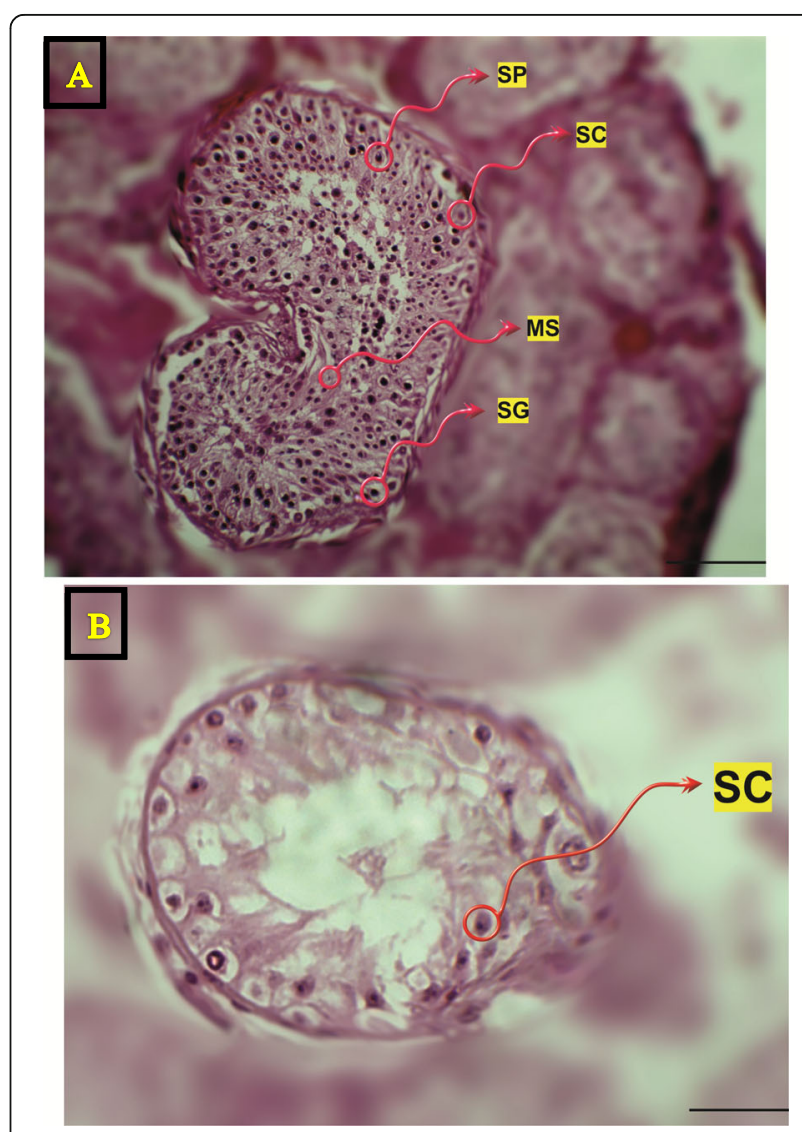

Fig. 1 a Testicular sections of samples with OA (obstructive azoospermia). b Testicular segments of specimens by SCOS (Sertoli cell-only syndrome). $\mathrm{SP}=$ spermatocyte; $\mathrm{MS}=$ mature spermatid; SC = Sertoli cell; SG = spermatogonia; Scale bar $=20 \mu \mathrm{m}$ 


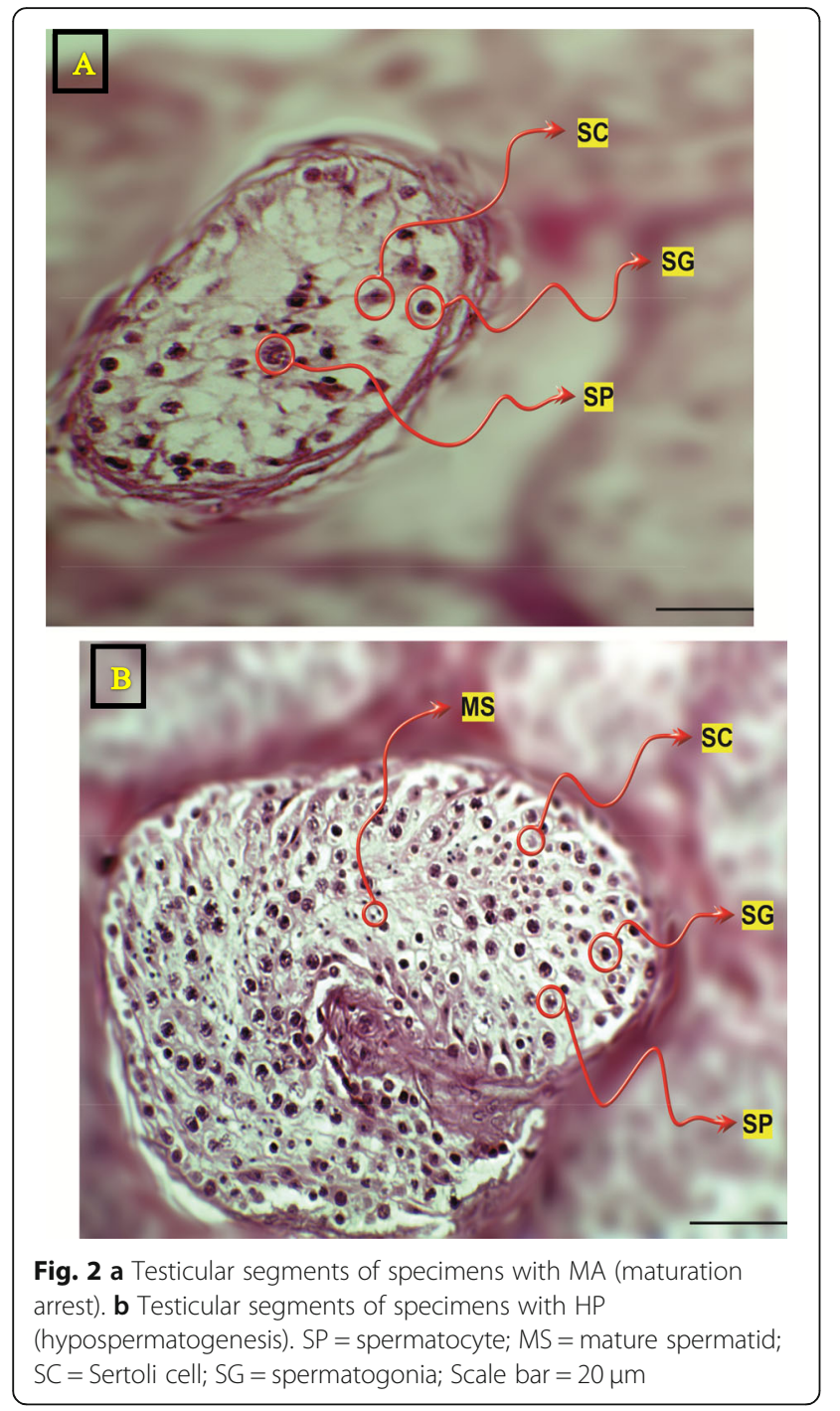

protection of germ cells against transposons [22, 23]; however, up to now their role in human spermatogenesis has not been well studied. The present study investigated the gene expression and protein levels of TDRD1, TDRD5, TDRD9 and TDRD12 genes in testicular tissue of NOA patients in comparison with OA patients.

Recent studies in mice models have demonstrated that Tdrd5 gene plays an important role in silencing of LINE-1, a transposon member of the long interspersed nuclear elements (LINE), which is involved in assembly of polar granules in germ cells, chromatoid bodies, and spermatogenesis $[24,25]$. Previous projects showed that TDRD1 in prospermatogonia, arrange a complex with Mili (mouse homologue of PIWIL2), also TDRD9 is a vital partner of Miwi2 (mouse homologue of PIWIL4). The studies proved that the TDRD1 and TDRD9 are involved in biogenesis of primary and secondary piRNAs, transposon repression and accuracy of meiosis phase [15, 26-29]. TDRD12 has a crucial role in the final stage

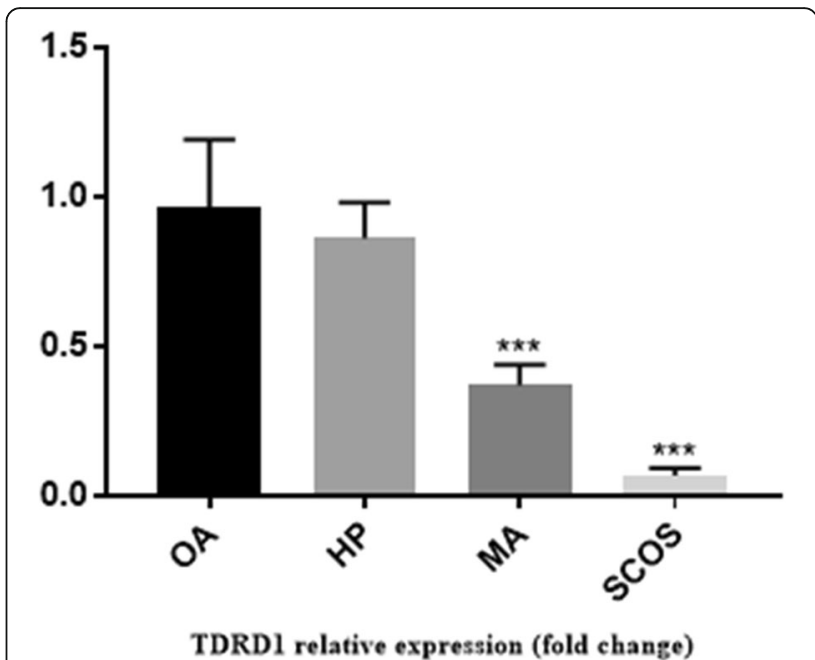

Fig. 3 Comparison of the expression levels of TDRD1 between HP, MA, SCOS, and OA(control) patients. ${ }^{* *} p<0.001$

of meiosis phase, secondary piRNAs biogenesis and transposon silencing.

The lack of expression of TDRD genes found in SCOS was a common observation in this study, suggesting that the transcription of these genes could be limited to germ cells. Due to the lack of germ cells in SCOS, it seems likely that the expression levels of TDRD genes in the SCOS samples would not be detected. However, we did detect very low levels of expression of these genes in some individuals, which could show the existence of small foci of spermatogenesis in these specimens or mixed patterns in NOA subtypes. Western blot analysis results confirmed the findings from qPCR, and demonstrated lack of TDRD expression in SCOS samples. Because the expression of

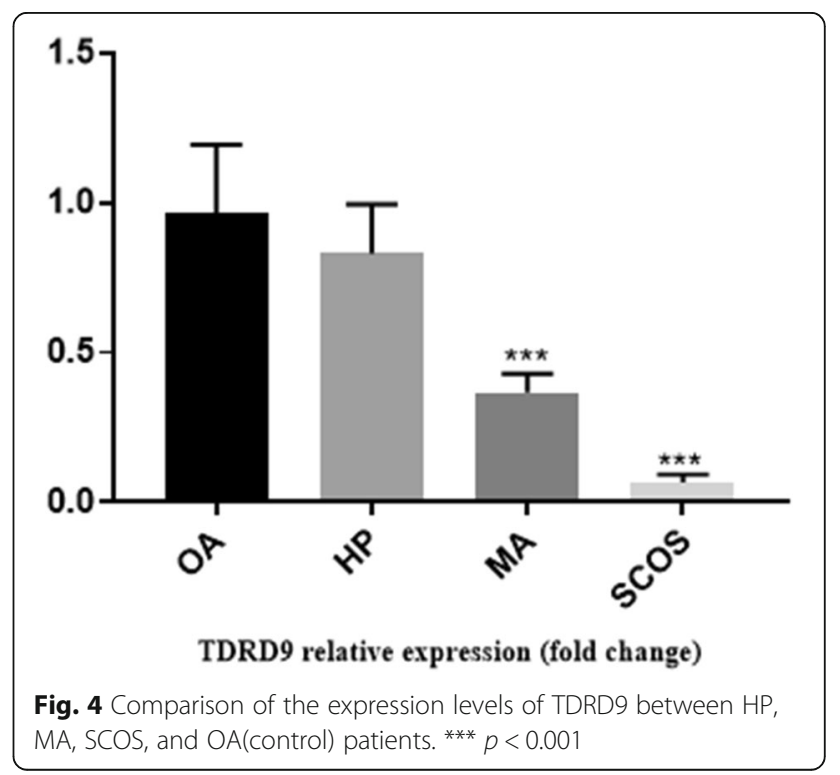




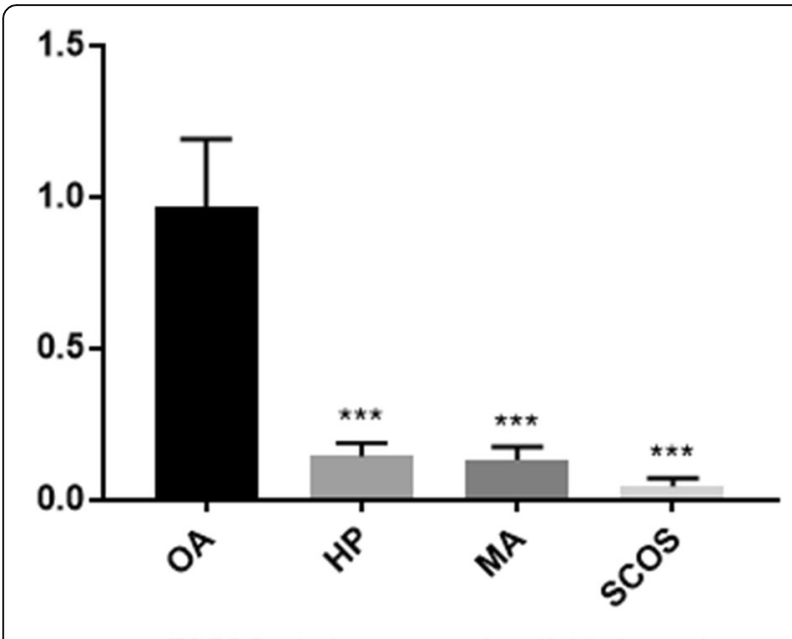

TDRD5 relative expression (fold change)

Fig. 5 Comparison of the expression levels of TDRD5 between HP, MA, SCOS, and OA(control) patients. ${ }^{* *} p<0.001$

the TDRDs genes was found to be very limited in the qPCR technique in SCOS specimens, but not in the Western blot technique, this difference could be attributed to the inherent nature of the Western blot technique, which does not reveal very low protein expression.

We also found that TDRD1 expression was significantly downregulated in the MA group versus controls. In Mili knockout mouse models, infertility of male mice has been shown to be due to stopping spermatogenesis at zygotenepachytene stages. It has been revealed that hypermethylation of TDRD1 may lead to spermatogenic dysfunction [30]. Xiao-Bin Zhu et al. [31] identified the SNP rs77559927 in TDRD1 was related to a diminished risk of spermatogenic malfunction [29]. Western blot analysis results confirmed

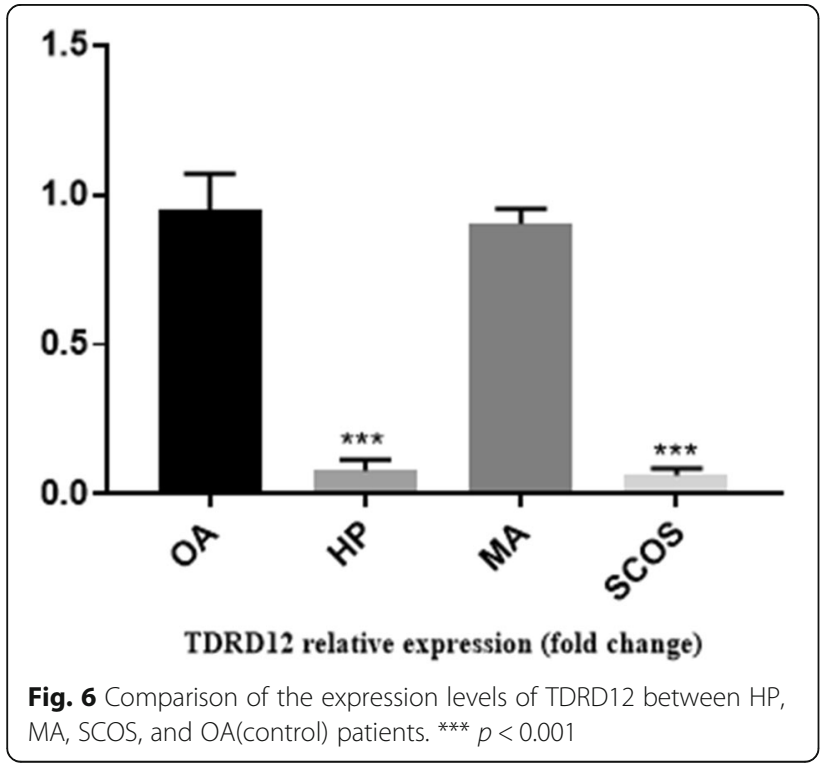

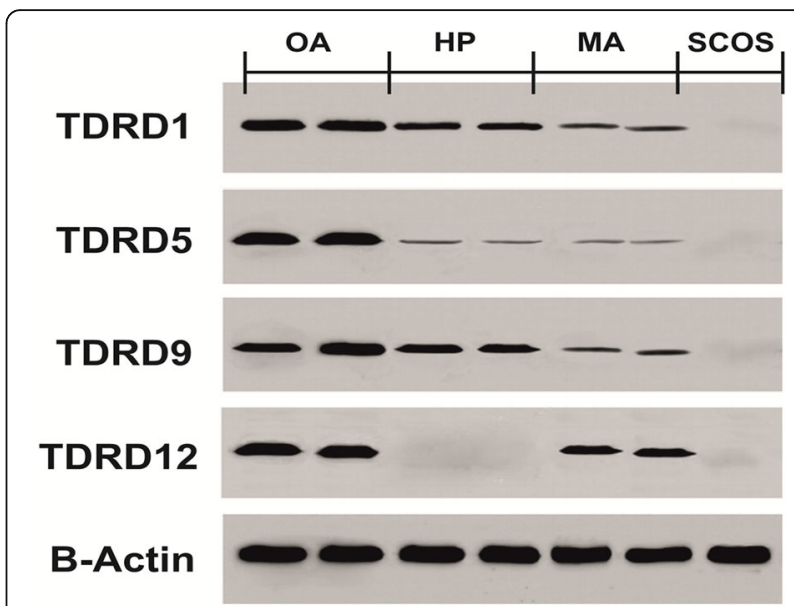

Fig. 7 Western blotting test results for protein expression of TDRDs genes in $\mathrm{HP}, \mathrm{MA}$, SCOS, and OA samples compared to control group

that the protein encoded by the TDRD1 gene had low expression in MA samples. The results of this experiment could confirm the role of TDRD1 in the early stages of meiosis process, likely to suppress transposons, which is essential for the progression of human spermatogenesis.

Another finding of this study was that the expression of TDRD5 was significantly reduced in almost all cases (SCOS, MA and HP) compared to controls. Mitinori Saitou et al. reported that loss of Tdrd5 leads to absence of spermatozoa, transposon depression and infertility [25]. Tdrd5 $5^{-1-}$ mutations were arrested round spermatid and disorganized of chromatoid bodies [24]. The results of Western blot analysis also showed that the TDRD5 protein had a very low expression in almost all samples. These results revealed that TDRD5 is not restricted to prospermatogonia, unlike TDRD1, TDRD5 has more activity [25]. TDRD5 could have the same function in humans and mouse models, which plays a central role in the whole process of spermatogenesis.

The TDRD9, in collaboration with the HIWI2 (human homologue of PIWIL4), has a substantial effect on the synthesis of the piRNAs. In Tdrd $9^{-/-}$mutants, the whole quantity of piRNAs were entirely reduced in testis [27]. Faruk Hadziselimovic et al. showed that cryptorchid boys with defected expression of TDRD9 have a high risk of infertility due to transposon desilencing [32]. Two separate studies in the population of Iran and China reported a significant relationship between HIWI2 gene rs508485 polymorphism and increased risk of spermatogenesis defects $[33,34]$. Arafat et al. reported the relationship between the deletion frameshift mutation in TDRD9 and NOA [35]. In present study, expression of TDRD9 like TDRD1 showed a significantly decreased in the MA samples compared with OA samples. Western blot analysis results proved that the protein encoded by the TDRD9 gene had low expression in 
MA samples. It seems TDRD9 and TDRD1 have approximately the same role in human and other animals and they are very important for the meiosis process.

The TDRD12 is indirectly related to the TDRD1 and MILI, because it has a different location than they [36]. Jung-Jae Ko and colleagues revealed that TDRD12 is predominantly localized at the acrosome of the spermatid, which is completely different with other members of the TDRDs family [37]. In this study, TDRD12 exhibited a very low expression in HP specimens in comparison to OA specimens. In addition, Western blot analysis results proved that the protein encoded by the TDRD12 gene was not expressed in HP specimens. TDRD12 is contributing to a process that leads to compaction of the sperm nucleus, histone-to-protamine exchange, which is essential for the differentiation of round spermatid into spermatozoa [36]. TDRD12 could be part of the master regulators in the terminal processes of spermatogenesis, and might act without piRNAs. piRNAs are inactivated in the round spermatid stage [38].

\section{Conclusion}

To our knowledge, this study is the first to evaluate the expression of TDRD1, TDRD5, TDRD9 and TDRD12 genes in NOA and OA samples by qPCR and Western blot technique. Given the potential role for TDRDs in male infertility, our results suggest there is a need for further investigation to improve knowledge about the etiology of male infertility.

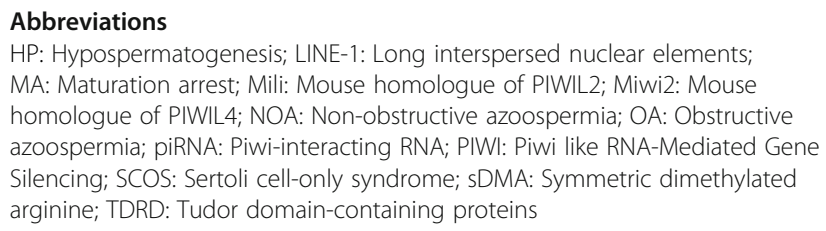

Abbreviations

HP: Hypospermatogenesis; LINE-1: Long interspersed nuclear elements; MA: Maturation arrest; Mili: Mouse homologue of PIWIL2; Miwi2: Mouse homologue of PIWIL4; NOA: Non-obstructive azoospermia; OA: Obstructive azoospermia; piRNA: Piwi-interacting RNA; PIWI: Piwi like RNA-Mediated Gene Silencing; SCOS: Sertoli cell-only syndrome; sDMA: Symmetric dimethylated arginine; TDRD: Tudor domain-containing proteins

\section{Acknowledgements}

The authors would like to thank to Dr. S.Mirjalili, Dr. Montazeri, Mr. Tajomolian, and Mr. Heydarian for their valuable support.

\section{Authors' contributions}

$E B$ and AK performing the main steps of essay and writing the manuscript. MA and MN Collecting the samples and helping to perform RNA extraction and GPCR. MH and MV Analysis of results and doing statistical tests. NG Head of team and monitoring and fixing technical errors during all steps of the study. SR and IA and YJ Contribute to Western blotting and manuscript editing. The authors read and approved the final manuscript.

\section{Funding}

No funding has been received for this experiment.

\section{Availability of data and materials}

The datasets generated and/or analyzed during the current study are available in the Google repository (following links). https://drive.google.com/ uc?export=download\&id=1V3IMH89MLOKK78Mhisa1BJLzsYKR84CB and https://drive.google.com/uc?export=download\&id=10NJDXr7SO4 ib0wlwLhfT2ds616w1seZF

\section{Ethics approval and consent to participate}

The Institutional Ethics Committee of the Shahid sadoughi University of Medical Sciences of Yazd approved the study design

(IR.SSU.MEDICINE.REC.1396.220) and written informed consent was obtained from each participant before the collection of tissue samples.

\section{Consent for publication}

Not applicable.

\section{Competing interests}

The authors declare that they have no competing interests.

\section{Author details}

${ }^{1}$ Department of Medical Genetics, Shahid Sadoughi University of Medical Sciences, Yazd, Iran. ${ }^{2}$ Medical Genetics Research Center, Shahid Sadoughi University of Medical Sciences, Yazd, Iran. ${ }^{3}$ Department of Cellular and Molecular Biology, Faculty of Science, Azarbaijan Shahid Madani University, Tabriz, Iran. ${ }^{4}$ Center of Pharmaceutical Sciences, Faculty of Life Sciences, University of Vienna, Vienna, Austria. ${ }^{5}$ School of Pharmacy, Faculty of Sciences, University of Rome Tor Vergata, Rome, Italy. ${ }^{6}$ Department of Biology, Faculty of Science, University of Guilan, Rasht, Iran. ${ }^{7}$ Genetics Centre, Molecular and Clinical Sciences Institute, St George's University of London, London, UK. ${ }^{8}$ Abortion Research Centre, Yazd Reproductive Sicences Institue, Shahid sadoughi University of Medical Sciences, Yazd, Iran.

Received: 4 October 2019 Accepted: 10 February 2020

Published online: 14 February 2020

\section{References}

1. Olszewska M, Wanowska E, Kishore A, Huleyuk N, Georgiadis AP, Yatsenko AN, et al. Genetic dosage and position effect of small supernumerary marker chromosome (sSMC) in human sperm nuclei in infertile male patient. Sci Rep. 2015;5:17408.

2. Jarow JP, Espeland MA, Lipshultz LI. Evaluation of the azoospermic patient. J Urol. 1989;142(1):62-5.

3. Jarow JP. Diagnostic approach to the infertile male patient. Endocrinol Metab Clin N Am. 2007:36(2):297-311.

4. Okada H, Tajima A, Shichiri K, Tanaka A, Tanaka K, Inoue I. Genome-wide expression of azoospermia testes demonstrates a specific profile and implicates ART3 in genetic susceptibility. PLoS Genet. 2008;4(2):e26.

5. Lee JY, Dada R, Sabanegh E, Carpi A, Agarwal A. Role of genetics in azoospermia. Urology. 2011;77(3):598-601.

6. Jarvi K, Lo K, Fischer A, Grantmyre J, Zini A, Chow V, et al. CUA guideline: the workup of azoospermic males. Can Urol Assoc J. 2010;4(3):163.

7. Ma M, Yang S, Zhang Z, Li P, Gong Y, Liu L, et al. Sertoli cells from non-obstructive azoospermia and obstructive azoospermia patients show distinct morphology, Raman spectrum and biochemical phenotype. Hum Reprod. 2013;28(7):1863-73.

8. Donoso $P$, Tournaye $H$, Devroey $P$. Which is the best sperm retrieval technique for non-obstructive azoospermia? A systematic review. Hum Reprod Update. 2007;13(6):539-49.

9. Cao C, Wen Y, Wang X, Fang N, Yuan S, Huang X. Testicular piRNA profile comparison between successful and unsuccessful micro-TESE retrieval in NOA patients. J Assist Reprod Genet. 2018;35(5):801-8.

10. Tóth KF, Pezic D, Stuwe E, Webster A. The piRNA pathway guards the germline genome against transposable elements. InNon-coding RNA and the Reproductive System. Dordrecht: Springer; 2016. p. 51-77.

11. Aravin AA, Van Der Heijden GW, Castañeda J, Vagin W, Hannon GJ, Bortvin A. Cytoplasmic compartmentalization of the fetal piRNA pathway in mice. PLoS Genet. 2009:5(12):e1000764

12. Carmell MA, Girard A, Van De Kant HJ, Bourc'his D, Bestor TH, de Rooij DG, et al. MIWI2 is essential for spermatogenesis and repression of transposons in the mouse male germline. Dev Cell. 2007;12(4):503-14.

13. Kuramochi-Miyagawa S, Kimura T, ljiri TW, Isobe T, Asada N, Fujita Y, et al. Mili, a mammalian member of piwi family gene, is essential for spermatogenesis. Development. 2004;131(4):839-49.

14. Brower-Toland B, Findley SD, Jiang L, Liu L, Yin H, Dus M, et al. Drosophila PIWI associates with chromatin and interacts directly with HP1a. Genes Dev. 2007:21(18):2300-11.

15. Chen C, Jin J, James DA, Adams-Cioaba MA, Park JG, Guo Y, et al. Mouse Piwi interactome identifies binding mechanism of Tdrkh Tudor domain to arginine methylated Miwi. Proc Natl Acad Sci. 2009;106(48):20336-41. 
16. Pillai RS, Chuma S. piRNAs and their involvement in male germline development in mice. Develop Growth Differ. 2012;54(1):78-92.

17. Hosokawa M, Shoji M, Kitamura K, Tanaka T, Noce T, Chuma S, et al. Tudorrelated proteins TDRD1/MTR-1, TDRD6 and TDRD7/TRAP: domain composition, intracellular localization, and function in male germ cells in mice. Dev Biol. 2007;301(1):38-52

18. Liu K, Chen C, Guo Y, Lam R, Bian C, Xu C, et al. Structural basis for recognition of arginine methylated Piwi proteins by the extended Tudor domain. Proc Natl Acad Sci. 2010;107(43):18398-403.

19. He Y, Luo M, Yi M, Sheng Y, Cheng Y, Zhou R, et al. Identification of a testisenriched heat shock protein and fourteen members of hsp70 family in the swamp eel. PLoS One. 2013;8(6):e65269.

20. de Kretser DM, Loveland KL, Meinhardt A, Simorangkir D, Wreford N Spermatogenesis. Human Reprod. 1998;13(suppl_1):1-8.

21. Yuan $\mathrm{S}$, Mcswiggin $H$, Zheng $H$, Yan W. A testis-specific gene, Ubqlnl, is dispensable for mouse embryonic development and spermatogenesis. Mol Reprod Dev. 2015;82(6):408.

22. Sukthaworn S, Panyim S, Udomkit A. Functional characterization of a cDNA encoding Piwi protein in Penaeus monodon and its potential roles in controlling transposon expression and spermatogenesis. Comp Biochem Physiol A Mol Integr Physiol. 2019;229:60-8.

23. Demoliou C. piRNAs-Transposon Silencing and Germ Line Development. InGenomic Elements in Health, Disease and Evolution. New York: Springer; 2015. p. 47-81.

24. Smith JM, Bowles J, Wilson M, Teasdale RD, Koopman P. Expression of the tudor-related gene Tdrd5 during development of the male germline in mice. Gene Expr Patterns. 2004;4(6):701-5.

25. Yabuta Y, Ohta H, Abe T, Kurimoto K, Chuma S, Saitou M. TDRD5 is required for retrotransposon silencing, chromatoid body assembly, and spermiogenesis in mice. J Cell Biol. 2011;192(5):781-95.

26. Deng W, Lin H. Miwi, a murine homolog of piwi, encodes a cytoplasmic protein essential for spermatogenesis. Dev Cell. 2002;2(6):819-30.

27. Shoji M, Tanaka T, Hosokawa M, Reuter M, Stark A, Kato Y, et al. The TDRD9MIWI2 complex is essential for piRNA-mediated retrotransposon silencing in the mouse male germline. Dev Cell. 2009;17(6):775-87.

28. Siomi MC, Mannen T, Siomi H. How does the Royal Family of Tudor rule the PIWl-interacting RNA pathway? Genes Dev. 2010;24(7):636-46.

29. Zhu X, Zhi E, Li Z. MOV10L1 in piRNA processing and gene silencing of retrotransposons during spermatogenesis. Reproduction. 2015;149(5):R229-R35.

30. Chuma S, Hosokawa M, Kitamura K, Kasai S, Fujioka M, Hiyoshi M, et al Tdrd1/Mtr-1, a tudor-related gene, is essential for male germ-cell differentiation and nuage/germinal granule formation in mice. Proc Natl Acad Sci. 2006;103(43):15894-9.

31. Zhu X-B, Lu J-Q, Zhi E-L, Zhu Y, Zou S-S, Zhu Z-J, et al. Association of a TDRD1 variant with spermatogenic failure susceptibility in the Han Chinese. J Assist Reprod Genet. 2016;33(8):1099-104.

32. Hadziselimovic F, Hadziselimovic N, Demougin P, Krey G, Oakeley E. Deficient expression of genes involved in the endogenous defense system against transposons in cryptorchid boys with impaired mini-puberty. Sex Dev. 2011;5(6):287-93.

33. Gu A, Ji G, Shi X, Long Y, Xia Y, Song L, et al. Genetic variants in Piwiinteracting RNA pathway genes confer susceptibility to spermatogenic failure in a Chinese population. Hum Reprod. 2010;25(12):2955-61.

34. Kamaliyan Z, Pouriamanesh S, Amin-Beidokhti M, Rezagholizadeh A, Mirfakhraie R. HIWI2 rs508485 polymorphism is associated with non-obstructive azoospermia in iranian patients. Rep Biochem Mol Biol. 2017;5(2):108.

35. Arafat M, Har-Vardi I, Harlev A, Levitas E, Zeadna A, Abofoul-Azab M, et al. Mutation in TDRD9 causes non-obstructive azoospermia in infertile men. J Med Genet. 2017;54(9):633-9.

36. Pandey RR, Tokuzawa Y, Yang Z, Hayashi E, Ichisaka T, Kajita S, et al. Tudor domain containing 12 (TDRD12) is essential for secondary PIWI interacting RNA biogenesis in mice. Proc Natl Acad Sci. 2013;110(41):16492-7.

37. Kim M, Ki BS, Hong K, Park S-p, Ko J-J, Choi Y. Tudor domain containing protein TDRD12 expresses at the acrosome of spermatids in mouse testis. Asian-Australas J Anim Sci. 2016;29(7):944.

38. Gou L-T, Kang J-Y, Dai P, Wang X, Li F, Zhao S, et al. Ubiquitination-deficient mutations in human Piwi cause male infertility by impairing histone-toprotamine exchange during spermiogenesis. Cell. 2017;169(6):1090-104. e13.

\section{Publisher's Note}

Springer Nature remains neutral with regard to jurisdictional claims in published maps and institutional affiliations.
Ready to submit your research? Choose BMC and benefit from:

- fast, convenient online submission

- thorough peer review by experienced researchers in your field

- rapid publication on acceptance

- support for research data, including large and complex data types

- gold Open Access which fosters wider collaboration and increased citations

- maximum visibility for your research: over $100 \mathrm{M}$ website views per year

At BMC, research is always in progress.

Learn more biomedcentral.com/submissions 